\title{
UPAYA PENYANDANG DISABILITAS FISIK TERHADAP AKSES PEKERJAAN DALAM PEMENUHAN KEBUTUHAN SOSIAL EKONOMI (Studi Pada Perkumpulan Penyandang Disabilitas Indonesia (PPDI) Provinsi Sulawesi Tenggara)
}

Pirda Wahyuningsi ${ }^{1}$, Sulsalman Moita ${ }^{2}$, Tanzil ${ }^{3}$

${ }^{123}$ Fakultas Ilmu Sosial dan Ilmu Politik Universitas Halu Oleo

E-mail: firdawahyuningsi3099@gmail.com, moitasulsalman@yohoo.co.id, tanzilsosio@gmail.com
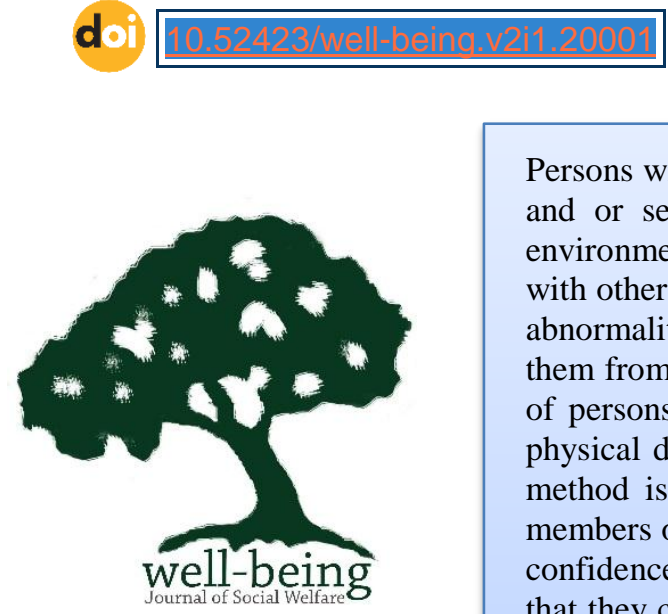

Persons with disabilities are every person who experiences physical, intellectual, mental and or sensory limitations for a long period of time who in interacting with the environment experiences obstacles and difficulties to participate fully and effectively with other citizens based on equal rights, a physical disability is someone who has body abnormalities in the locomotion which include bones, muscles and joints that prevent them from doing proper activities. The purpose of this research is to find out the efforts of persons with physical disabilities and the challenges experienced by persons with physical disabilities in accessing jobs in meeting socio-economic needs. This research method is descriptive qualitative. The results showed that first, the efforts made by members of PPDI Sultra in meeting their socio-economic needs, namely increasing selfconfidence by working and also joining an environment that has conditions like them so that they can encourage each other and also by participating in training for people with disabilities. gain knowledge and skills to equip them to open and get jobs as well as entrepreneurship, entrepreneurship, namely sewing, welding workshops, and selling groceries. Second, the challenges experienced by PPDI Sultra members with regard to access to jobs in meeting socio-economic needs, namely employment opportunities that are not disability friendly, shame, job opportunities, education and skills. With the efforts made by persons with physical disabilities to access work in meeting their socioeconomic needs, they get recognition from the community that they are able to have a job and fulfill their needs.

Keywords: Physical Disabilities, Socio-Economic Needs, Persons with Disabilities, Efforts

\section{PENDAHULUAN}

Era globalisasi sekarang ini, memang dituntut hasil-hasil kerja yang serba cepat perusahan dan instansi penyedia lapangan kerja menginginkan kinerja yang optimal dari para tenaga kerjanya akan tetapi tidak semua sumber daya manusia memiliki kapasitas yang sama. Keanekaragam khususnya terkait kondisi fisik seseorang menjadi pertimbangan pemilik dunia usaha dan/atau penyedia lapangan kerja dalam memilih tenaga kerja yang mereka gunakan. Untuk mendapatkan suatu pekerjaan, kaum difabel memiliki ruang gerak yang cukup terbatas. Dimana banyak perusahaan atau lembaga yang merekrut seorang pekerja sering menegaskan kritetria umum yaitu sehat jasmani dan rohani. Dengan syarat tersebut tentu secara tidak langsung menutup akses pekerjaan untuk penyandang disabilitas (Junaedi, 2003).

Dalam Undang-Undang Nomor 13 Tahun 2003 tentang Ketenagakerjaan Pasal 31 disebutkan bahwa "Setiap tenaga kerja mempunyai hak dan kesempatan yang sama untuk mendapatkan pekerjaan dan memperoleh penghasilan yang layak di dalam atau di luar negeri”. Pengakuan tersebut menyebutkan bahwa (1) Pemerintah, Pemerintah Daerah, Badan Usaha Milik Negara, dan Badan Usaha Milik Daerah wajib mempekerjakan paling sedikit 2\% (dua persen) Penyandang 
Disabilitas dari jumlah pegawai atau pekerja; (2) Perusahaan swasta wajib mempekerjakan paling sedikit 1\% (satu persen) Penyandang Disabilitas dari jumlah pegawai atau pekerja.

Tetapi, karena dengan keterbatasannya masih banyak perusahaanperusahaan belum mampu mengakomodir penyandang disabilitas menjadi bagian tenaga kerja dan bahkan mereka seolaholah teralienasi dari lingkungan pekerjaan. Padahal sama seperti masyarakat yang normal mereka juga membutuhkan pekerjaan untuk menghidupi diri sendiri dan keluarganya dalam aspek ekonomi. Di dunia kerja, peluang bagi penyandang disabilitas untuk bersaing juga masih rentan stigma sosial dimana masyarakat menganggap bahwa kaum disabilitas tidak mampu bersaing dalam dunia kerja(Harahap dan Bustanudin, 2015).

Jumlah penyandang disabilitas yang cukup banyak di Sulawesi Tenggara khususnya yang berada di Kota Kendari, maka para penyandang disabilitas memiliki inisiatif untuk membentuk sebuah organisasi khusus untuk para penyandang disabilitas dan diberi nama Perkumpulan Penyandang Disabilitas Indonesia (PPDI) Provinsi Sulawesi Tenggara. Dengan terbentuknya organisasi perkumpulan penyandang disabilitas Indonesia (PPDI) Sultra, para penyandang disabilitas khususnya yang ada di kota Kendari akan sangat membantu mereka dalam hal konsultasi yang berkaitan dengan kedisabilitasan, peningkatan kesejahteraan penyandang disabilitas dengan meningkatkan kepercayaan diri serta mengikuti pelatihan para penyandang disabilitas bisa mendapatkan pengetahuan dan keterampilan untuk bekal mereka membuka dan dan mendapatkan pekerjaan serta berwirausaha yang dilakukan seperti menjahit, membuka bengkel las, dan berjualan sembako agar dapat berdaya berdaya mandiri guna membawa perubahan untuk pemenuhan kebutuhan sosial ekonominya.

Melihat fenomena tersebut peneliti ingin melakukan penelitian mendalam mengenai Upaya Penyandang Disabilitas Fisik Terhadap Akses Pekerjaan Dalam Pemenuhan Kebutuhan Sosial Ekonomi (Studi Pada Perkumpulan Penyandang Disabilitas Indonesia (PPDI) Provinsi Sulawesi Tenggara).

\section{METODE PENELITIAN}

Penelitian ini dilaksanakan tepatnya pada Perkumpulan Penyandang Disabilitas Indonesia (PPDI) Provinsi Sulawesi Tenggara. Alasan memilih tempat ini adalah karena ingin mengungkapkan realitas di balik fakta yang terjadi pada para penyandang disabilitas terkait dengan lapangan pekerjaan dalam pemenuhan kebutuhan sosial ekonomi dengan fakta sesuai dengan peraturan perundang-undangan.

Penentuan informan dalam penelitian ini menggunakan teknik purposive sampling, yaitu pemilihan informan dengan pertimbangan tertentu, dengan anggapan bahwa informan paling mengerti tentang informasi yang peneliti harapkan sehingga memudahkan peneliti menjelajahi objek atau situasi sosial tertentu. Adapun informan dalam penelitian ini yaitu: Ketua Perkumpulan Penyandang Disabilitas Indonesia (PPDI) Provinsi Sulawesi Tenggara, Anggota Perkumpulan Penyandang Disabilitas Indonesia (PPDI) Provinsi Sulawesi Tenggara sebanyak 8 orang (Tuna Daksa 6 Orang. Tuna Netra Low vision 2 Orang), Tenaga Istruktur Pelatihan Kewirausahaan 1 Orang.

Teknik pengumpulan data yang dilakukan adalah penelitian lapangan yaitu dengan Observasi (pengamatan) Observasi yang dilakukan peneliti adalah pada saat penentuan informan dimana peneliti mengamati secara visual menggunakan 
indera mata dan telinga sendiri Wawancara Proses menggali data terhadap informan dengan menggunakan pedoman wawancara terbuka dan disertai dengan wawancara lebih mendalam terhadap informan (indepthsinterview). Serta Dokumentasi berupa gambar/foto pada saat kejadian berlansung.Data dan informasi tertulis dapat diperoleh dari literature, dokumen yang ada tentang Upaya Penyandang Disabilitas Fisik Terhadap Akses Pekerjaan Dalam Pemenuhan Kebutuhan Sosial Ekonomi, pada Perkumpulan Penyandang Disabilitas Indonesia (PPDI) Provinsi Sulawesi Tenggara.

Teknis analisis data dalam penelitian ini, menggunakan model Miles dan Huberman (1984) dalam Upe (2016 : 113-115), aktivitas dalam analisis data kualitatif dilakukan secara interaktif dan berlangsung secara terus menerus sampai tuntas. Yaitu Data Reduction (Reduksi Data), Data Display (Penyajian Data), Conclusion Drawing/Verification (Penarikan Kesimpulan/verifikasi).

\section{HASIL DAN PEMBAHASAN}

PPDI Sultra merupakan singkatan dari Perkumpulan Penyandang Disabilitas Indonesia Provinsi Sulawesi Tenggara yang dewan pengurus cabangnya berada di kota kendari. PPDI Sultra terbentuk pada tahun 1997 dan awalnya dinamakan Perkumpulan Penyandang Cacat Indonesia (PPCI), namun pada tahun 2016 berganti nama menjadi PPDI. Saat ini PPDI Sultra di ketuai oleh Pak Ali Sahid yang menjabat sebagai ketua sejak tahun 2018. Tujuan PPDI adalah memperjuangkan pemenuhan hak-hak penyandang disabilitas agar memperoleh kesamaan kesempatan dalam segala aspek kehidupan dan penghidupan serta dapat berpartisipasi penuh dalam pembangunan nasional. Adapun Jumlah ragam disabilitas anggota PPDI Sultra, sebagai berikut:
Table 1.1 Jumlah Ragam Disabilitas anggota PPDI Sultra

\begin{tabular}{|c|c|c|}
\hline No. & Ragam Disabilitas & Jumlah \\
\hline 1 & Tuna Rungu & 22 orang \\
\hline 2 & Tuna Grahita & 62 orang \\
\hline 3 & Tuna Daksa & 190 orang \\
\hline 4 & Tuna Wicara & 12 orang \\
\hline 5 & $\begin{array}{c}\text { Mental (Gangguan } \\
\text { Jiwa) }\end{array}$ & 179 orang \\
\hline 6 & Low Vision & 16 orang \\
\hline 7 & Total Blind & 44 orang \\
\hline 8 & Lambat Belajar & 13 orang \\
\hline 9 & Down Syndrome & 19 orang \\
\hline 10 & Disabilitas Ganda & 469 orang \\
\hline 11 & $\begin{array}{c}\text { Pydg Ekpsk } \\
\text { dengan pyk. } \\
\text { Kronis }\end{array}$ & 10 orang \\
& Parang \\
\hline
\end{tabular}

Sumber : Data PPDI Sultra

a. Upaya Penyandang Disabilitas Fisik Terhadap Akses Pekerjaan Dalam Pemenuhan Kebutuhan Sosial Ekonomi di PPDI Sultra

\section{Meningkatkan Kepercayaan Diri}

Permasalahan yang dihadapi oleh anggota PPDI Sultra adalah banyak anggota PPDI Sultra yang merasakan pengalaman berat pasca amputasi tangan atau kaki. Mereka merasa sulit untuk menerima kondisi fisiknya yang tidak lengkap. Begitu juga dengan anggota PPDI Sultra yang mengalami gangguan penglihatan atau dalam hal ini Tuna Netra yang sulit beradaptasi dalam masyarakat karena memiliki gangguan penglihatannya. penyandang disabilitas meskipun saat ini mereka terlihat begitu semangat dalam menjalani kehidupannya, mereka juga pernah berada pada fase yang membuat mereka trauma dengan kondisi yang mereka alami, dimana mereka malu untuk berinteraksi dengan orang-orang sekitarnya. Seperti upaya yang dilakukan oleh Pak Kasim Babu untuk membangun kembali kepercayaan dirinya dengan cara bekerja yaitu mendaftarkan diri menjadi 
seorang Pegawai Negeri Sipil (PNS) dan juga bergabung menjadi anggota PPDI Sultra. Selain itu, dengan bergabung pada sebuah komunitas yang dimana anggotanya juga memiliki kondisi yang sama, bisa membuat mereka lebih semangat dan percaya diri. Dalam komunitas tersebut, mereka bisa melihat bahwa ternyata banyak orang yang memiliki nasib yang sama bahkan lebih sulit dari pada kondisinya dan disitulah mereka tergerak hatinya untuk bangkit.

Upaya yang dilakukan untuk membangun kepercayan diri seorang Tuna Netra adalah adalah mau mencoba sesuatu hal yang baru dengan mengandalkan potensi dalam hal pendengaran, perabaan, dan juga ingatannya. Dengan potensi itulah dia bisa menjadi seorang tukang pijat. Sehingga dengan begitu bisa memenuhi kebutuhan sosialnya dalam hal ini rasa percaya dirinya bisa kembali dan tidak merasa minder lagi dalam menjalani kehidupan sehari-harinya. Membangun kepercayaan diri para penyandang disabilitas sangat berguna untuk bisa mengeksplorasi potensi dirinya dan mencoba melakukan hal yang bermanfaat untuk dirinya dengan cara bekerja.

\section{Pelatihan}

$\begin{array}{lrr} & \text { Pelatihan merupakan proses } \\ \text { transfer ilmu pengetahuan dan }\end{array}$ keterampilan. Dari proses pelatihan tersebut mengajarkan individu dengan keterampilan dasar yang mereka butuhkan untuk menjalankan pekerjaan mereka dengan maksimal. Dari pelatihan itulah para penyandang disabilitas bisa mendapatkan pengetahuan dan keterampilan untuk menjadi bekal mereka membuka dan mendapatkan pekerjaan. Anggota PPDI Sultra dominan banyak yang sebagai wirausaha, olehnya itu dengan pelatihan kewirausahaan yang diberikan bisa memberikan wawasan tentang kewirausahaan sehingga mendorong untuk pertumbuhan usaha yang lebih besar dan bisa meningkatkan penghasilan. Selain pelatihan kewirausahaan, upaya lain yang dilakukan oleh anggota PPDI Sultra yang menggeluti bidang jahit juga pernah mendapatkan pelatihan menjahit sebelumnya. Namun yang berbeda adalah mereka dikirim ke BLK oleh Dinas Sosial. Sebelum di masukkan ke BLK untuk pelatihan menjahit, mereka memang belum memiliki keterampilan sama sekali.

\section{Wirausaha}

Kewirausahaan merupakan proses kegiatan yang melibatkan kreatifitas dan inovasi untuk memberikan manfaat atau bernilai lebih bagi diri sendiri dan orang lain. Jiwa wirausaha berlaku untuk semua orang baik untuk mereka yang memiliki kondisi fisik normal maupun yang memiliki keterbatasan/kekurangan kondisi fisiknya yang dikategorikan dalam disabilitas. kewirausahaan juga menjadi pembuktian yang mampu menolak stigma negatif tentang penyandang disabilitas yang tidak berdaya dan perlu dikasihani. Seperti informan berikut Ibu Muliawati setelah sebelumnya mengikuti pelatihan menjahit, kemudian terus mengasah ilmu yang didapatkan kini Ibu Muliawati memulai membuka usahanya dengan menjahit. Kemudian informan atas nama Pak Agustang yang mengalami kecacatan pasca amputasi kaki kanan beliau dengan mengandalkan keterampilan yang didapatkan dari belajar dengan orang-orang terdekat/tetangga mampu membuka usaha bengkel las dan bahkan memperkerjakan orang-orang yang fisiknya sempurna. Serta informan atas nama Pak La Ode Islamiah dengan keterbatasan yang dialami tetapi tetap optimis berupaya untuk mencari nafka dengan membuka usaha berjualan sembako. 


\section{b. Tantangan Penyandang Disabilitas Fisik Terhadap Akses Pekerjaan Dalam Pemenuhan Kebutuhan Sosial Ekonomi di PPDI Sultra}

Memiliki kesempatan yang sama dalam bekerja adalah sebuah kondisi yang dimana pemerintah sebagai penanggung jawab dalam memberikan perlindungan hak dan memberikan peluang dan menyediakan akses pekerjaan yang sama bagi penyandang disabilitas fisik, agar supaya para penyandang disabilitas fisik dapat menyalurkan kemampuan dan potensinya dalam berbagai bidang termasuk juga dalam hal bekerja.

\section{Stigma Negatif}

Dalam kehidupan bermasyarakat tidak jarang para anggota PPDI Sultra yang mengalami disabilitas fisik dianggap sebagai subjek yang berbeda dan lemah serta berbeda dengan manusia norma lainnya, sehingga mereka juga dipandang tidak mampu dalam disertakan pada bidang pekerjaan. Stigma tersebut muncul pada beberapa perusahaan bahwa penyandang disabilitas dengan keterbatasan fisik yang dimiliki, nantinya akan sulit menghadapi pekerjaan dan sulit beradaptasi dengan lingkungan kerja yang ada.

\section{Rasa Malu}

Penyandang disabilitas yang mengalami rasa malu atas kondisi fisik yang mereka alami menjadikan mereka pribadi yang kurang berani tampil dimuka publik. Hal ini yang menjadi kendala bagi penyandang disabilitas dalam mendapatkan pekerjaan karena potensi yang mereka miliki tidak dapat terlihat dan tidak dapat diketahui oleh orang banyak. penyandang disabilitas yang sebelumnya memiliki kondisi fisik yang normal, dan tiba-tiba mengalami disabilitas adalah sebuah kendala besar bagi mereka. Dimana setelah mengalami disabilitas sudah tidak berani lagi mencoba pekerjaan yang mereka sering kerjakan semasa kondisi fisiknya masih sempurna.

\section{Kesempatan Kerja}

Sesuai dengan Pasal UU Nomor 8 Tahun 2016, khususnya Pasal 53 ayat (1) yang dimana, Pemerintah, Pemerintah Daerah, Badan Usaha Milik Negara (BUMN), dan Badan Usaha Milik Daerah wajib mempekerjakan paling sedikit 2 persen penyandang disabilitas dari jumlah pegawai atau pekerja. Begitupun perusahaan swasta wajib mempekerjakan paling sedikit 1 persen penyandang disabilitas. Dalam dunia kerja di era globalisasi saat ini memang banyak menuntut sumber daya manusia yang berkualitas. Namun tidak sedikit juga yang masih mengalami diskriminasi/penolakan dimana pencari kerja yang memenuhi standar kesehatan fisik masih mengalami kesulitan untuk mendapatkan pekerjaan, terutama kesempatan bagi penyandang disabilitas yang masih mengalami hal serius dalam mengakses kesempatan kerja. Berbagai tantangan-tantangan yang dialami oleh para penyandang disabilitas untuk dapat mengakses pekerjaan yang layak bagi mereka.

\section{Pendidikan}

Dunia pekerjaan saat ini bahkan perusahaan-perusahaan masih mensyaratkan pendidikan tinggi sebagai syarat dapat diterima dalam pekerjaan tersebut, dimana pekerja harus mempunyai pendidikan minimal sekolah menegah atas atau kejuruan, Diploma I,II,III,IV dan Sarjana. Ini menjadi tantangan tersendiri bagi penyandang disabilitas karena kebanyakan penyandang disabilitas fisik masih belum memiliki latar belakang pendidikan sebagaimana yang disyaratkan dalam bekerja, selain itu pendidikan khusus bagi penyandang disabilitas sangat sedikit 
sekali sehingga para penyandang disabilitas sulit mendapatkan pendidikan yang sesuai dengan kemampuan dan kondisi fisiknya terutama pendidikan khusus bagi penyandang disabilitas fisik dewasa.

\section{Keterampilan/Skill}

Keterampilan merupakan suatu kemampuan didalam menggunakan akal, pikiran, ide serta kreatifitas dalam mengerjakan, mengubah atau juga membuat sesuatu itu menjadi lebih bermakna sehingga dari hal tersebut menghasilkan sebuah nilai dari hasil pekerjaan. Hal yang paling banyak menjadi tantangan bagi penyandang disabilitas untuk bisa mendapatkan pekerjaan itu karena kurangnya keterampilan yang dimiliki teman-teman disabilitas.

\section{KESIMPULAN}

Berdasarkan dari hasil pembahasan sebelumnya maka dapat disimpulkan bahwa para penyandang disabilitas yang tergabung dalam PPDI Sultra, para penyandang disabilitas berupaya untuk bisa mengakses pekerjaan agar bisa memenuhi kebutuhan sosial ekonominya. Adapun upaya yang mereka lakukan adalah: Pertama, Meningkatkan kepercayaan diri dengan cara bekerja dan juga bergabung dengan lingkungan yang memiliki kondisi seperti mereka sehingga mereka bisa saling memberikan semangat. Kedua, Pelatihan, dengan pelatihan para penyandang disabilitas bisa mendapatkan pengetahuan dan keterampilan untuk menjadi bekal mereka membuka dan mendapatkan pekerjaan. Ketiga, Berwirausaha, wirausaha yang dilakukan yaitu menjahit, bengkel las, dan menjual sembako.

Dalam mengakses pekerjaan ada banyak tantangan yang dihadapi oleh para penyandang disabilitas, diantaranya :
Pertama, lapangan pekerjaan saat ini, utamanya bagi perusahaan-perusahaan masih belum bisa membuka lowongan pekerjaan bagi para penyandang disabilitas, karena mereka mengganggap bahwa penyandang disabilitas belum mampu menjalankan pekerjaan seperti orang yang kondisi fisiknya sempurna. Padahal mereka belum mencoba untuk mempekerjakan para penyandang disabilitas. Kedua, Rasa Malu Penyandang disabilitas yang mengalami rasa malu atas kondisi fisik yang mereka alami menjadikan mereka pribadi yang kurang berani tampil dimuka publik. Dimana setelah mengalami disabilitas sudah tidak berani lagi mencoba pekerjaan yang mereka sering kerjakan semasa kondisi fisiknya masih sempurna. Ketiga, Kesempatan Kerja. Saat ini kesempatan kerja bagi para penyandang disabilitas itu sudah sangat minim, bahkan bisa di bilang hampir lowongan pekerjaan bagi disabilitas yang ada di Kota Kendari hampir tidak ada. Keempat, Pendidikan. syarat untuk bisa mendapatkan pekerjaan adalah pernah menempuh pendidikan tinggi, sedangkan anggota PPDI Sultra sendiri banyak yang tidak pernah menempuh pendidikan tinggi. Hal itulah yang menjadi tantangan para penyandang disabilitas untuk bisa mengakses pekerjaan. Kelima, Keterampilan/Skill. tantangan penyandang disabilitas dalam mengakses pekerjaan adalah ada penyandang disabilitas yang tidak memiliki keterampilan dan juga pelatihan yang diajarkan terkadang tidak sesuai dengan kemampuan mereka.

Namun, dengan upaya yang dilakukan para penyandang disabilitas fisik untuk bisa mengakses pekerjaan dalam memenuhi kebutuhan sosial ekonominya akan mendapatkan pengakuan dari masyarakat bahwa meskipun para penyandang disabilitas memiliki keterbatasan tapi mereka juga 
mampu memenuhi kebutuhan sosial ekonominya tanpa harus menjadi beban buat orang lain dan mampu memiliki pekerjaan.

\section{DAFTAR PUSTAKA}

Harahap, Rahayu Repindowaty dan Bustanuddin. 2015. "Perlindungan Hukum Terhadap Penyandang Disabilitas Menurut Convention On The Rights of Persons With Disabilities (CRPD)". INOVATIF| Jurnal Ilmu Hukum,8(1) (pp. 17-29).

Junaedi, C. Marliana. Mengelola Diversitas: Penyebab Kegagalan dan Model yang Efektif. Kinerja Volume7, No 1, Tahun 2003. Hal 22-28.

Undang-Undang Nomor 8 Tahun 2016.

Tentang Defenisi dan Ragam Penyandang Disabilitas.

Undang-Undang Nomor 13 Tahun 2003 Tentang Ketenagakerjaan.

Upe, Ambo. 2016. Metode Penelitian Sosial (Filosofi dan Desain Praktis). Kendari. Literacy Institute 